\title{
REVIEW
}

\section{Critical Appraisal on Orbital Decompression for Thyroid Eye Disease: A Systematic Review and Literature Search}

\author{
Konstadinos G. Boboridis · Jimmy Uddin • Dimitrios G. Mikropoulos • \\ Catey Bunce - George Mangouritsas · Irini C. Voudouragkaki • \\ Anastasios G. P. Konstas
}

To view enhanced content go to www.advancesintherapy.com

Received: February 3, 2015 / Published online: July 23, 2015

(C) The Author(s) 2015. This article is published with open access at Springerlink.com

\section{ABSTRACT}

Introduction: Orbital decompression is the indicated procedure for addressing exophthalmos and compressive optic neuropathy in thyroid eye disease. There are an abundance of techniques for removal of orbital bone, fat, or a combination published in the scientific literature. The relative efficacy and complications of these interventions in relation to the specific indications remain as yet undocumented. We performed a systematic review of the current published evidence for the effectiveness of orbital decompression,

K. G. Boboridis - I. C. Voudouragkaki ·

A. G. P. Konstas $(\square)$

1st University Department of Ophthalmology,

Aristotle University of Thessaloniki, 1 Kyriakidi

Street, 54636 Thessaloniki, Greece

e-mail: konstas@med.auth.gr

K. G. Boboridis · D. G. Mikropoulos •

A. G. P. Konstas

3rd University Department of Ophthalmology,

Aristotle University of Thessaloniki, Thessaloniki,

Greece

K. G. Boboridis · J. Uddin · C. Bunce

Moorfields Eye Hospital, London, UK

G. Mangouritsas

Eye Clinic, General Hospital "Red Cross", Athens, Greece possible complications, and impact on quality of life.

Methods: We searched the current databases for medical literature and controlled trials, oculoplastic textbooks, and conference proceedings to identify relevant data up to February 2015. We included randomized controlled trials (RCTs) comparing two or more interventions for orbital decompression.

Results: We identified only two eligible RCTs for inclusion in the review. As a result of the significant variability between studies on decompression, i.e., methodology and outcome measures, we did not perform a meta-analysis. One study suggests that the transantral approach and endonasal technique had similar effects in reducing exophthalmos but the latter is safer. The second study provides evidence that intravenous steroids may be superior to primary surgical decompression in the management of compressive optic neuropathy requiring less secondary surgical procedures.

Conclusion: Most of the published literature on orbital decompression consists of retrospective, uncontrolled trials. There is evidence from those studies that removal of the medial and 
lateral wall (balanced) and the deep lateral wall decompression, with or without fat removal, may be the most effective surgical methods with only few complications. There is a clear unmet need for controlled trials evaluating the different techniques for orbital decompression. Ideally, future studies should address the effectiveness, possible complications, quality of life, and cost of each intervention.

Keywords: Decompression;

DON; Exophthalmos; Graves'; GO; Orbit; Orbitopathy; Strabismus; TED; Thyroid

\section{INTRODUCTION}

\section{Definition and Epidemiology}

Graves' orbitopathy (GO) or thyroid eye disease (TED) is a disabling ocular presentation of Graves' disease (GD), causing cosmetic changes and functional alterations. TED will present in almost $50 \%$ of GD cases, whereas approximately $5 \%$ of patients will develop severe disease with dysthyroid compressive optic neuropathy (DON) [1]. Recent epidemiological studies show that GD has an incidence of 210 per million per year in Sweden, presenting more frequently in the fifth decade of life. It more frequently affects women than men, with a female to male ratio of $4: 1$. TED It is an autoimmune disorder with an incidence of 42 per million per year [2]. The orbit is affected due to expression of organ-specific autoantibodies against the thyroid stimulating receptor (TSH receptor) which presents both in thyroid and periocular tissues [3]. Moderate-to-severe and very severe GO will develop in $5-6 \%$ of GD cases, whereas mild GO resolves spontaneously in most cases $[4,5]$. Clinical presentation involves inflammation of the orbital and periocular tissues, edema of the extraocular muscles, and fat proliferation, which increase the orbital volume, resulting in exophthalmos and eyelid retraction. Restrictive ocular myopathy due to muscle enlargement and fibrosis result in diplopia. Eyelids, conjunctiva, and caruncle most frequently develop erythema and swelling due to inflammation [6].

TED manifests initially with an active inflammatory stage followed by a burnt out fibrotic phase. Management of the active disease is based on euthyroidism, anti-inflammatory and immunosuppressive agents, or retrobulbar radiotherapy guided by the disease activity and severity scores [7]. However, functional and esthetic recovery in the fibrotic stage may be incomplete, and residual tissue scarring combined with permanent periocular changes result in persistent exophthalmos, diplopia, and lid retraction, which require multiple rehabilitative surgical interventions $[8,9]$. Finally, the disease significantly diminishes the quality of life [10].

\section{Intervention}

Orbital decompression is the indicated intervention to restore optic nerve function in cases with DON, to correct or prevent exposure keratopathy due to lagophthalmos, and to rehabilitate patients with disfiguring exophthalmos. Surgery is performed by removing orbital bone, fat, or both and has only been applied for cosmetic rehabilitation in the 1990s [11-13]. It aims for the removal of medial, lateral, and inferior bony walls; this expands the orbital space into the paranasal sinuses and therefore increases the total volume. The literature suggests that three-wall 
decompression is indicated in cases with high degrees of proptosis, whereas two-wall decompression is more appropriate for cases with less exophthalmos [14-18]. Removal of the deep lateral wall maximizes the decompressive effect [19]. The addition of fat removal increases the safety of the procedure and the magnitude of proptosis reduction $[20,21]$.

There is extensive literature describing the various techniques for orbital decompression but there is no consensus on the most efficient and safe intervention $[8,12,13,20,22-27]$. The inclusion of different indications, in different stages of natural history and the lack of uniform method for motility evaluation have skewed the comparative results [28, 29].

The present study summarizes the current evidence-based data on the efficacy of surgical orbital decompression for TED and possible information on complications and quality of life.

\section{METHODS}

The foundation of this review is a previously conducted systematic review and meta-analysis for the Cochrane Collaboration [22]. We did not require the approval of our institutional review board as the analysis in this article evaluates previously conducted studies and does not involve any new studies of human or animal subjects performed by any of the authors. Reporting of the methodology and results of the systematic review was guided by the PRISMA guidelines [30].

\section{Inclusion Criteria}

The review includes unrestricted randomized controlled trials (RCTs) resulting from a detailed search strategy. In addition, review or large case series non-randomized studies will be analyzed.

\section{Outcome Measures}

Primary outcome is considered the success rate compared to the failures as defined in each study by means of composite scores [31, 32] or ordinal score [33]. Outcomes are evaluated from 1 to 6 months following surgery. Secondary outcomes include the post-decompression corrective procedures for pre-existing conditions like motility and eyelid alterations, disease severity measured by the NOSPECS score [34], or the total eye score [35], and exophthalmometry measurements of disease activity evaluated with the clinical activity score [36].

Adverse outcomes are considered surgery-induced strabismus or visual loss, other possible complications, and discontinuations of treatment. Where available, quality of life data measured with the Graves' ophthalmopathy quality of life tool (GO-QOL), a disease-specific validated questionnaire will be included [37].

\section{Literature Search Methods}

We searched CENTRAL which contains the Cochrane Eyes and Vision Group Trials Register (2015, Issue 1), part of The Cochrane Library (http://www.thecochranelibrary.com), MEDLINE (January 1950 to February 2015), EMBASE (January 1980 to February 2015), PubMed (January 1948 to February 2015), the metaRegister of Controlled Trials (mRCT) (http://www.controlled-trials.com), and Clinical Trials.gov (http://www.clinicaltrials.gov), with no language or date restrictions. The most updated electronic database search was on 2 March 2015, based on the strategy suggested by Glanville et al. [38] (see "Appendix").

The reference lists of the included trials were assessed with the Science Citation Index for possible publications that cited the included 
trials in this review. We contacted investigators and experts in the field for additional trials.

\section{Data Collection and Analysis}

Search results screened for appropriate studies. We reviewed the full text of studies with relevance to the review and assessed for methodological quality those that met the selection criteria. Disagreements were resolved by discussion. We extracted data onto a standardized data extraction form, reconciled differences and resolved disagreements before contacting investigators for further information where data was unclear.

\section{Risk of Bias Assessment}

Included trials were assessed for risk of bias following Higgins et al.'s methodology [39]. Possible areas for risk of bias were selection process and sequence generation, incomplete outcome data, and selective outcome reporting, classifying each trial as low, unclear, or high risk of bias.

For measures of treatment effect we followed the methodology for Systematic Reviews of Interventions suggested by Deeks et al. [40]. We used the odds ratio for the primary outcome measure (success or failure of treatment) as reported data was dichotomous. A possible unit of analysis issue is the inclusion of both eyes from participants with no provision for this in the analysis. When relevant data from the included studies was unclear or incomplete, we contacted the investigators for the missing information.

Variety of study designs and methodological differences would normally produce some degree of heterogeneity. Should more trials be included in future updates, we will assess statistical heterogeneity and consistency between using the $I^{2}$ statistic and funnel plot analysis for publication bias. The two included studies revealed substantial clinical heterogeneity and meta-analysis of the results was not appropriate; we therefore present a descriptive summary of results supplemented with clinically important data from excluded studies.

\section{Compliance with Ethics}

The analysis in this article is based on previously conducted studies and does not involve any new studies of human or animal subjects performed by any of the authors.

\section{RESULTS}

\section{Results of Search Strategy}

The updated electronic searches revealed 1195 titles, 160 more than the published Cochrane review [22]. After removing duplicated and irrelevant results, we scanned 1058 records and discarded 914 titles because they were outside the scope of our review. From the remaining 144 references, there were no additional RCTs identified from the ones that were included in our systematic review (Fig. 1). Clinically meaningful information from the excluded 142 studies supplemented the results in a descriptive outline. Personal communication with the European Group for Graves Ophthalmopathy (EUGOGO) revealed a protocol for RCT comparing three surgical techniques of orbital decompression but this is in the early stages with no study registration yet.

\section{Included Studies}

Only two RCTs were eligible for inclusion in the review $[41,42]$. As a result of methodological 


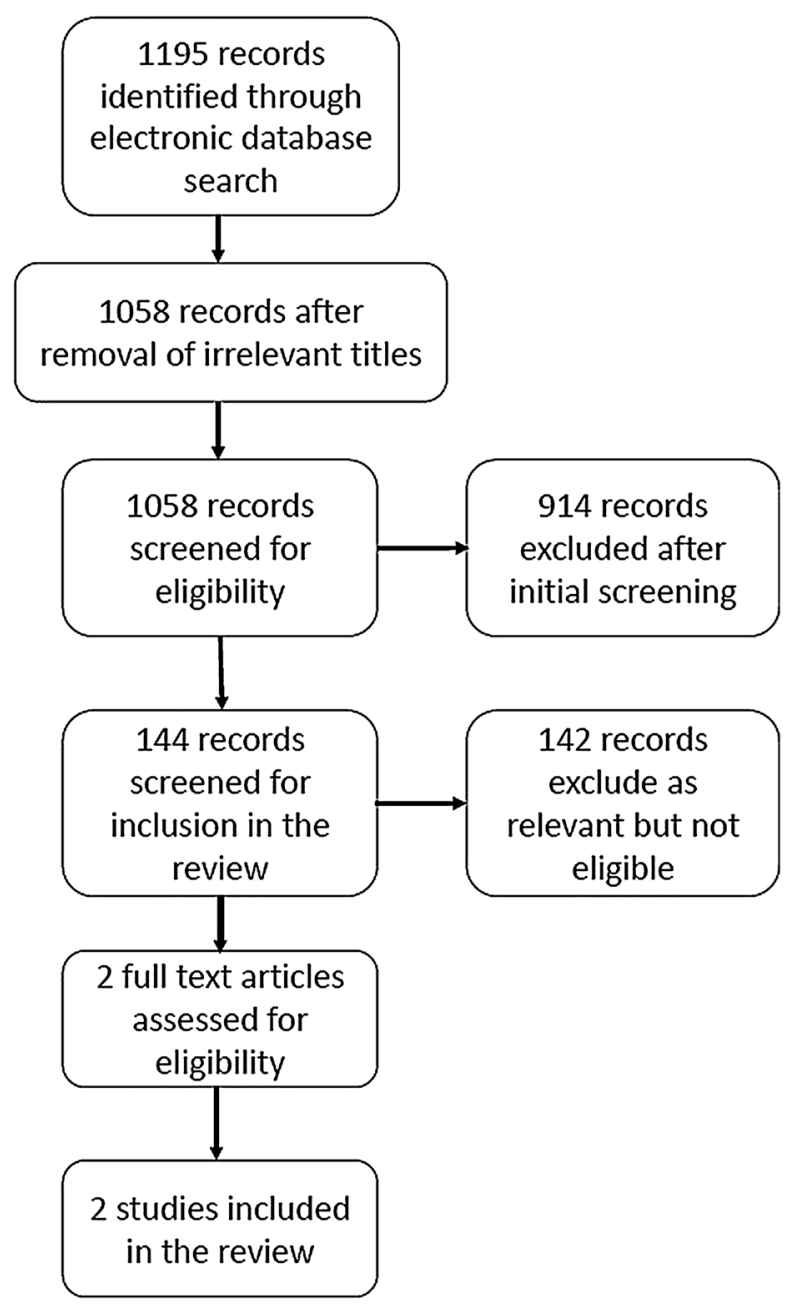

Fig. 1 Flow diagram of the study process. Search and identification of studies for inclusion in the review

and clinical heterogeneity no meta-analysis was performed and we present the results individually.

Pliego-Maldonado et al. [41] compared the Walsh-Ogura transantral approach with Kennedy's endoscopic endonasal technique for orbital decompression for TED (Table 1). Both methods produced similar reduction of exophthalmos. There was no data on composite outcome, clinical activity, or total eye scores. Similarly, no secondary outcomes were reported. The Walsh-Ogura technique was associated with higher rates of complication, mainly diplopia and infraorbital nerve damage (Table 2).

In the second study, Wakelkamp et al. [42] compared the surgical bony wall removal via a coronal approach with the intravenous administration of methylprednisolone for DON (Table 3). There was an improvement in visual acuity, total eye and clinical activity scores at 52 weeks post treatment). Success was reported in $56 \%$ of the steroid group and $17 \%$ of the surgical group in cases of DON (Table 4).

Additional interventions were recorded in a mean follow-up of 64 months for the surgery group where five out of six participants needed immunosuppression and three out of six needed squint surgery, followed by eyelid surgery in five out of six. Similarly, within 78 months in the steroids group, four out of nine had a decompression, and later five out of nine participants needed squint surgery, followed by eyelid surgery in four out of nine. From the total number of 15 randomized participants, only two did not require rehabilitative surgery and they were both in the steroids group. Five participants in the same group did not undergo surgical decompression (Table 5). Treatment side effects were more frequent in the steroids group and included weight gain and a cushingoid appearance in 12 out of 15 patients, hypertension and reversible hyperglycemia in one case, and visual deterioration in one eye due to retinal vein occlusion. Side effects of surgery were transient infraorbital hypoesthesia in four out of 14 participants, and strabismus in one participant.

\section{Risk of Bias in Included Studies}

Sequence generation was unclear in Pliego-Maldonado et al.'s study [41] because their randomization method was not stated. Wakelkamp et al. [42] randomized patients following pretreatment stratification using 
Table 1 Characteristics of included study by Pliego-Maldonado

Methods Randomized controlled trial. More than one eye per participant was included

Participants Patients with Graves' disease exophthalmos $(>22 \mathrm{~mm})$ who were euthyroid for at least 6 months after treatment

26 eyes in 17 participants were decompressed using the Walsh-Ogura technique (group 1)

18 eyes of 18 participants were decompressed using the Kennedy's surgical approach (group 2)

Gender ratio 11 male, 24 female

Group 1 mean age 42.8 years SD (14.6); group 2 mean age 36.7 years SD (11.4)

Interventions Walsh-Ogura technique was compared with the Kennedy's surgical approach

Outcomes Exophthalmos measurements, diplopia infraorbital nerve lesion

Notes Paper published in Spanish

Risk of bias

\begin{tabular}{|c|c|c|}
\hline Bias & Authors' judgment & Support for judgment \\
\hline Random sequence generation (selection bias) & Unclear risk & $\begin{array}{l}\text { No details are given regarding sequence } \\
\text { generation }\end{array}$ \\
\hline Allocation concealment (selection bias) & High risk & No evidence of concealment \\
\hline $\begin{array}{l}\text { Blinding (performance bias and detection bias) } \\
\text { All outcomes }\end{array}$ & High risk & $\begin{array}{l}\text { It is not stated that the physicians or } \\
\text { participants were masked to the } \\
\text { intervention used }\end{array}$ \\
\hline $\begin{array}{l}\text { Incomplete outcome data (attrition bias) } \\
\text { All outcomes }\end{array}$ & Low risk & $\begin{array}{l}\text { Exophthalmometry measures and } \\
\text { complications were presented in tables }\end{array}$ \\
\hline Selective reporting (reporting bias) & Low risk & No evidence of selective reporting \\
\hline
\end{tabular}

Table 2 Comparison of the adverse events related to two surgical methods for orbital decompression

\begin{tabular}{llll}
\hline Study & Outcome & Walsh-Ogura & Kennedy \\
\hline Pliego-Maldonado & Diplopia & $22 / 26$ eyes & $13 / 18$ eyes \\
& Infection & $3 / 26$ eyes & $0 / 18$ eyes \\
& Intraorbital nerve lesion & $13 / 26$ eyes & $0 / 18$ eyes \\
\hline
\end{tabular}

envelopes in two blocks of four per block. Potential risks of bias for both trials are the lack of allocation concealment of intervention assignment and no evidence of masking. Both studies adequately addressed incomplete outcome data and clearly reported the main outcome measures.

The excluded studies identified by our search strategy did not provide credible evidence for decompressive surgery. Their description of 
Table 3 Characteristics of included study by Wakelkamp

Methods Randomized controlled trial. If participants did not respond they were switched to the other treatment arm; however the last observation prior to the switch was used in the analysis

Participants Participants with very active Graves' ophthalmology and optic neuropathy aged between 18 and 80 years. Participants already treated with corticosteroids or any other treatment such as surgery or radiotherapy were excluded. Patients were included if they had at least five or more of the first seven items used to determine clinical activity score and at least one of the last three. Pinhole visual acuity of $<0.63$ due to optic neuropathy and not due to corneal problems alone or other pre-existing eye disease

Interventions Surgical decompression-a three-wall coronal decompression versus methylprednisolone iv pulses $1 \mathrm{~g}$ daily for three consecutive days, repeated after 1 week, followed from day 15 onwards by oral prednisolone for 4 months in a tapering dose

Outcomes Primary outcome was change in visual acuity. Clinical activity score was reported. Response was evaluated at 26 weeks after therapy started or earlier if initial therapy failed

\section{Risk of bias}

\begin{tabular}{|c|c|c|}
\hline Bias & Authors' judgment & Support for judgment \\
\hline Random sequence generation (selection bias) & Low risk & $\begin{array}{l}\text { Randomization was performed after stratification } \\
\text { for pre-treatment and in two blocks of four } \\
\text { per block using envelopes }\end{array}$ \\
\hline Allocation concealment (selection bias) & Unclear risk & $\begin{array}{l}\text { It is not stated how the envelopes were assigned } \\
\text { to participants and opened }\end{array}$ \\
\hline $\begin{array}{l}\text { Blinding (performance bias and detection bias) } \\
\text { All outcomes }\end{array}$ & High risk & $\begin{array}{l}\text { The physicians or participants were not masked } \\
\text { to the intervention }\end{array}$ \\
\hline $\begin{array}{l}\text { Incomplete outcome data (attrition bias) } \\
\text { All outcomes }\end{array}$ & Low risk & There was no incomplete data \\
\hline Selective reporting (reporting bias) & Low risk & No evidence of selective reporting \\
\hline
\end{tabular}

Table 4 Relative successes of surgical orbital decompression versus medical treatment

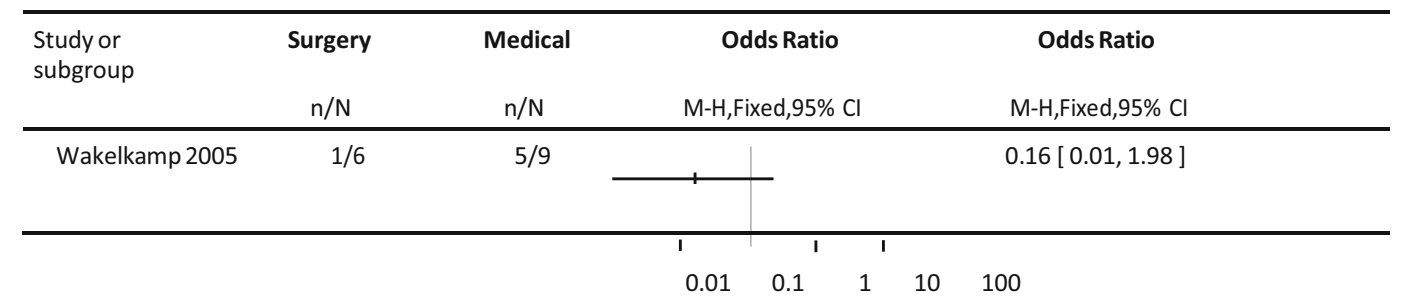

surgical technique and outcome data varies significantly; there is identifiable bias in the surgical preference and considerable underreporting of potential complications from a larger cohort of patients. It is therefore inconclusive to present their findings in detail 
Table 5 Adverse events of surgical orbital decompression versus medical treatment

\begin{tabular}{llll}
\hline Study & Squint surgery & Eye lid surgery & $\begin{array}{l}\text { Lack of response pinhole } \leq \mathbf{0 . 6 3} \\
\text { Signs of optic neuropathy at 26 weeks }\end{array}$ \\
\hline Wakelkamp 2005 & At long-term follow-up & At long-term follow-up & $5 / 6$ surgical patients \\
& $3 / 6$ surgical patients & $5 / 6$ surgical patients & $4 / 9$ steroid patients \\
& $5 / 9$ steroid patients & $4 / 9$ steroid patients & \\
\hline
\end{tabular}

and we only summarize their results in terms of technique effectiveness, indications, and complication rate.

A large multicenter study evaluated 139 euthyroid patients (248 orbits) with inactive GO who underwent decompressive surgery for disfiguring proptosis [28]. The procedure was performed by an ophthalmologist in nine of the 11 centers with the assistance of a maxillofacial surgeon in two, whereas endonasal decompression was performed by an ear, nose, and throat surgeon (ENT) in the remaining two. Three-wall decompression resulted in higher reduction of proptosis compared to the two-wall procedure despite the fact that the former was reserved for patients with significant preoperative proptosis. A linear regression analysis showed that the difference in surgical outcome was not due to the preoperative difference in exophthalmos alone. A subgroup analysis of cases with similar preoperative exophthalmos documented that the mean proptosis reduction after three-wall decompression was 5.8 (SD 1.7 ) $\mathrm{mm}$, significantly more than 4.6 (SD 1.0) $\mathrm{mm}$ after two-wall decompression.

The addition of fat removal augmented the effectiveness of the procedure but this only reached statistical significance in cases of three-wall decompression. Further analysis showed that the three-wall coronal approach produced significantly higher proptosis reduction compared to three-wall swinging eyelid ( \pm transcaruncular), three-wall translid, and endoscopic decompression, respectively. Similarly, as regards the two-wall procedures, the endoscopic approach resulted in significantly lower proptosis reduction compared with swinging eyelid and transconjunctival or transcaruncular approaches (Table 6).

The three-wall procedures were associated with more complications than two-wall decompressions and specifically in the coronal approach; complications were more frequent and severe. Adverse events included maxillary sinus obstruction, hypoglobus, and persistent eyelid swelling with scar dissatisfaction in the swinging eyelid three-wall procedures. Temporal bossing, paralysis of frontalis muscle, and cerebrospinal fluid (CSF) leak occurred after coronal approach, whereas the last of these also occurred with the endoscopic approach.

Consecutive diplopia developed in $35.7 \%$ of coronal approaches, $11 \%$ of the transconjunctival/transcaruncular two-wall decompression, and in $100 \%$ of the endoscopic group. These findings regarding effectiveness, complications, and motility disturbance are comparable to the published literature of uncontrolled trials, retrospective studies, and case reports. Published data suggests that three-wall decompression 


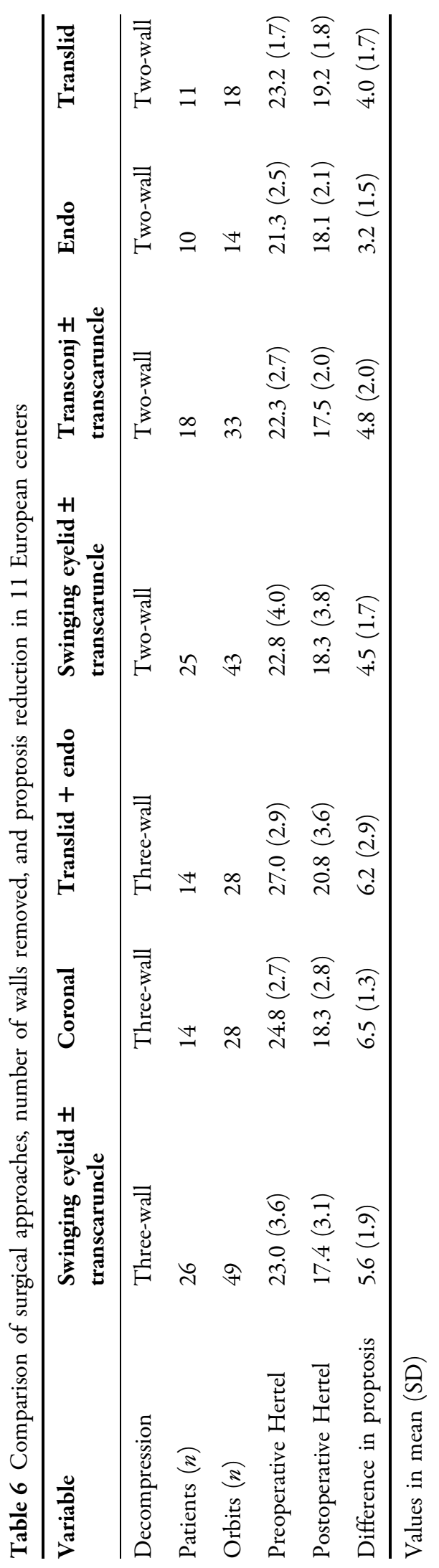

produces superior reduction proptosis than all the other methods but with high risk of potential complications, mainly induced diplopia, hypoglobus, and infraorbital nerve hypoesthesia [22, 43-48]. Less invasive procedures like the balanced two-wall decompression with or without endoscopic assistance for removal of the medial wall are gaining popularity because their satisfactory outcome relates to fewer complications and de novo strabismus [49-56].

Removal of the deep lateral wall may sufficiently decompress the orbital content and is becoming the procedure of choice either alone or in combination with other techniques. The published degree of proptosis reduction varies from $2.3 \mathrm{~mm}$ in the early reports [19] to a range of 3-7 $\mathrm{mm}$ with technique advancements [25, 57]. Total removal of the lateral orbital rim offers maximum globe retrodisplacement of up to $9 \mathrm{~mm}$ and augments the efficacy of the procedure $[58,59]$. Removal of the deep lateral wall is the safest decompressive procedure, associated with minimal if any complications. It has no significant effect on horizontal and vertical deviations with a low rate $(2.6 \%)$ of new onset diplopia, whereas in some cases preoperative diplopia was corrected after surgery $[19,60,61]$.

First-line treatment for DON consists of high dose intravenous steroids followed by urgent orbital decompression with removal of the medial wall offering the most effective relief of optic nerve compression [42, 62-67]. The transcaruncular approach to medial wall allows easy and safe access to the orbital apex for removal of the ethmoidal bone and maximum relief of optic nerve compression. This technique is only comparable to the endoscopic approach to medial wall and superior to all the other surgical 
decompression methods for the management of DON [65, 68-74].

Olivary first introduced removal of periocular fat for orbital decompression in 1991. The average amount of fat removed was $6.0 \mathrm{cc}$ and resulted in a $5.9-\mathrm{mm}$ reduction of proptosis which is comparable to the published results for removal of bony wall [75-77]. Other studies report contradictory results with more fat excision required per millimeter of proptosis reduction (mean $7.3 \mathrm{ml}$ of fat for a $4.7-\mathrm{mm}$ reduction) with the technique, producing significantly less reduction of exophthalmos [78-81]. Intraconal fat removal, alone or in combination with other techniques, may effectively alleviate optic nerve compression. The literature reports suggest it is comparable to bony decompression for the management of DON in selected cases [27, 72, 81, 82].

\section{DISCUSSION}

We did not find RCTs to support robust evidence for recommending a specific method for orbital decompression, as a result of the significant diversity of design, methodology, and outcome measures.

Pliego-Maldonado et al. [41] suggest that the Walsh-Ogura technique and Kennedy's transnasal approach are equally efficient in reducing exophthalmos but the latter is safer and associated with fewer adverse outcomes. Wakelkamp et al. [42] conclude that intravenous steroids are more efficient than primary surgical decompression for managing DON, requiring less corrective interventions in the long-term. The benefit of intravenous steroids on visual rehabilitation supersedes the higher incidence of transient side effects. Before more evidence becomes available, we cannot make documented recommendations for clinical practice.
Current practice may vary geographically and strongly relates to the preference of each medical specialty [13]. From the two procedures compared by Pliego-Maldonado et al. [41], the Walsh-Ogura was related to a higher incidence of complications and it is rarely used in current practice. Kennedy's transnasal approach is the preference of ENT surgeons for removal of the medial wall and is often combined with other techniques for maximizing outcome. Wakelkamp et al. [42] have documented the superiority of intravenous steroids for the management of DON but this trial was small and the observed difference was not statistically significant.

The body of evidence from the included studies does not allow for a documented conclusion regarding the objectives of this review. The study by Pliego-Maldonado et al. [41] is lacking information on allocation of treatment and masking and has a comparatively short follow-up period of 4 months. In contrast, Wakelkamp et al. [42] offer high methodological quality, but include a small number of patients (six and nine patients in each treatment arm) so that the observed difference between groups can be attributed to chance. The limited number of studies and the significant methodological diversity do not allow for a meta-analysis of the results. The available evidence relates to the review question but it is insufficient to address all the review objectives.

Potential risk of other sources of bias was unclear in both studies. This was due to the small number of patients in the Wakelkamp et al. study [42] and poor methodological quality and short follow-up in the Pliego-Maldonado et al. study [41]. Bias may distort systematic reviews and meta-analyses and encourages the use of questionable treatments [83]. This is not an issue for this 
review because of lack of adequate evidence to formulate recommendations for practice.

There are an abundance of published data on surgical orbital decompression for TED, mainly retrospective, cohort, and case series studies. These studies do not contribute to the development of documented guidelines for the efficacy and safety of a specific procedure except in cases of DON because they relate to different indications for decompression, different stages of TED with different outcome measures.

A descriptive summary of the available uncontrolled studies may suggest that three-wall decompression is the most effective procedure in reducing exophthalmos but is associated with a higher rate of complications, mainly hypoglobus and induced diplopia [28, $44,47,84]$. Surgical preference is shifting towards safer techniques with similar effect but fewer complications like the balance two-wall decompression or removal of the deep lateral wall $[19,25,28,60]$. Removal of the medial wall is indicated for relief of optic nerve compression in cases of DON and is better performed via transcaruncular or endoscopic approach [72, 73, 85]. Removal of periocular fat may alleviate the intraorbital pressure and is even effective in cases of DON [27, 72, 79, 80, 82]. In clinical practice, the techniques for removal of medial and lateral wall are often used in combination with or without endoscopic assistance and their result is augmented by additional fat removal [21, 72, 86-88].

Recent improvements in surgical technique have incorporated advanced technology for optimizing results and reducing complications. The application of stereotactic navigation systems offers accurate anatomical guidance in the surgical field and improves safety but with higher cost [89-91]. Changes in instrumentation for bone removal like ultrasonic versus high speed burring or microdebrider facilitate accurate tissue removal with less adverse events [92, 93]. A recent study evaluated a novel method for bone removal with the use of a piezosurgical device. It allows selective bone removal and therefore enhances surgical precision and, in theory, reduces the adverse events related to excessive trauma. Nevertheless, this technique offers no improvement in outcome or reduction in morbidity over conventional techniques [94].

\section{CONCLUSION}

\section{Implications for Practice}

The first included RCT [41] compared two surgical approaches for orbital decompression in patients with disfiguring TED. The treatments produced equal reduction of exophthalmos, but Kennedy's transnasal approach exhibited less surgical complications. These techniques are not routinely used by ophthalmologists and have been replaced by safer and more efficient approaches. Kennedy's endoscopic approach is still used by ENT and maxillofacial surgeons for the removal of the medial wall and is usually combined with other techniques for optimum decompression. The second included trial [42] compared three-wall bone removal versus intravenous steroid medical decompression for DON.

Several non-randomized studies suggest that three-wall decompression via coronal or swinging eyelid transconjunctival approach offers the best reduction of proptosis but is associated with higher rates of complication [13, 16, 23, 28, 52, 95-97]. Balanced decompression by removal of medial and lateral wall with or without fat removal may be more preferred for balancing optimum 
effectiveness with relative safety and fewer complications [22, 28, 62, 86, 98]. Recently, the deep lateral wall approach is gaining acceptance as it offers satisfactory decompression with minimum complications and can be combined with other techniques, mainly transcaruncle medial wall decompression with or without fat removal $[16,19,25,60,61,93]$. There are several reports that orbital fat removal is safer than and equally efficient as bony wall decompression [75-77, 99]. It may also relieve intraconal pressure on the optic nerve and improve visual function in cases with DON $[27,82,100]$. When combined with other techniques of bone removal it increases the efficacy of decompression and minimizes the rate of surgical complications [20, 21, 86]. These studies are non-randomized, mainly retrospective case series and non-comparative. It is therefore difficult to draw evidence-based conclusions regarding which method offers optimum decompression and has a lower complication rate. Similarly, we could not find evidence to compare the quality of life or the cost of any surgical technique in this condition. Recent supportive technological advances like stereotactic navigation, ultrasonic or piezosurgical bone removal have not yet proven to yield significant improvements in outcome or safety to justify the additional cost [94].

\section{Implications for Research}

There is a clear unmet need for well-structured, prospective randomized clinical trials to compare surgical methods for orbital decompression in TED. It is imperative to produce credible scientific evidence by evaluating and comparing the most effective currently used procedures of three-wall, balanced two-wall, deep lateral wall, and transcaruncle medial wall decompression with or without orbital fat removal.

Comparison of any of these or combination of approaches with another technique would also be valuable for formulating guidelines for future clinical practice. In cases of compressive optic neuropathy, comparison of surgical decompression with any form of anti-inflammatory and immunosuppressive treatment (medical decompression) would be necessary, as it has been documented that medical decompression is the best first-line treatment for DON [26, 42]. These studies must address primarily the following outcome measures: reduction of exophthalmos, disease severity (NOSPECS score), disease activity or composite outcome score, complication rate, quality of life, and cost of the intervention. Conducting a prospective RCT for a surgical intervention applicable only to a small percentage of patients suffering from TED which overall is considered a rare disease is a challenging but necessary undertaking and would require a multicenter collaboration of experts in the field such as EUGOGO in Europe and the International Thyroid Eye Disease Society (ITEDS) in the USA.

\section{ACKNOWLEDGMENTS}

The authors received no institutional and corporate funding or sponsorship for this study and article processing charges. All named authors meet the International Committee of Medical Journal Editors (ICMJE) criteria for authorship for this manuscript, take responsibility for the integrity of the work as a whole, and have given final approval for the version to be published. 
Conflict of interest. K. G. Boboridis, J. Uddin, D. G. Mikropoulos, C. Bunce, G. Mangouritsas, I. C. Voudouragkaki, and A. G. P. Konstas have no disclosures to declare.

Compliance with ethics guidelines. The analysis in this article is based on previously conducted studies and does not involve any new studies of human or animal subjects performed by any of the authors.

Open Access. This article is distributed under the terms of the Creative Commons Attribution Noncommercial License which permits any noncommercial use, distribution, and reproduction in any medium, provided the original author(s) and the source are credited.

\section{APPENDIX}

\section{Search strategy for MEDLINE}

1. randomized controlled trial.pt.

2. randomized or randomised).ab,ti.

3. placebo.ab,ti.

4. dt.fs.

5. randomly.ab,ti.

6. trial.ab,ti.

7. groups.ab,ti. 8 . or/1-7

9. exp animals/

10. exp humans/

11. 9 not (9 and 10)

12. 8 not 11

13. exp graves disease/

14. graves ophthalmopathy/

15. (grave $\$$ adj3 ophthalm $\$$ ).tw.

16. (grave $\$$ adj3 orbitopath\$).tw.

17. ((ophthalm\$ or eye\$) adj3 thyroid\$).tw.

18. (basedow $\$$ adj3 disease $\$$ ).tw.

19. exp exophthalmos/

20. (exophthalm\$ or proptos\$).tw.
21. exp optic nerve diseases/

22. ((disease $\$$ or neuropath $\$$ ) adj2 optic nerve\$).tw.

23. (TAO or TED).tw. 24. or/13-23

25. exp ophthalmological surgical procedures/

26. exp decompression, surgical/

27. decompress\$.tw. 28. or/25-27

29. 24 and 28

30. 12 and 29

\section{REFERENCES}

1. Wiersinga WM, Bartalena L. Epidemiology and prevention of Graves' ophthalmopathy. Thyroid. 2002;12:855-60.

2. Abraham-Nordling $\mathrm{M}$, Bystrom $\mathrm{K}$, Torring $\mathrm{O}$, et al. Incidence of hyperthyroidism in Sweden. Eur J Endocrinol. 2011;165:899-905.

3. Kendall-Taylor P. The pathogenesis of Graves' ophthalmopathy. Clin Endocrinol Metab. $1985 ; 14: 331-49$.

4. Laurberg P, Berman DC, Bulow Pedersen I, et al. Incidence and clinical presentation of moderate to severe Graves' orbitopathy in a Danish population before and after iodine fortification of salt. J Clin Endocrinol Metab. 2012;97:2325-32.

5. Tanda ML, Piantanida E, Liparulo L, et al. Prevalence and natural history of Graves' orbitopathy in a large series of patients with newly diagnosed Graves' hyperthyroidism seen at a single center. J Clin Endocrinol Metab. 2013;98:1443-9.

6. Perros P, Kendall-Taylor P. Thyroid-associated ophthalmopathy: pathogenesis and clinical management. Baillieres Clin Endocrinol Metab. 1995;9:115-35.

7. Krassas GE, Heufelder AE. Immunosuppressive therapy in patients with thyroid eye disease: an overview of current concepts. Eur J Endocrinol. 2001;144:311-8.

8. Bartalena L, Pinchera A, Marcocci C. Management of Graves' ophthalmopathy: reality and perspectives. Endocr Rev. 2000;21:168-99. 
9. Goldberg RA. Advances in surgical rehabilitation in thyroid eye disease. Thyroid. 2008;18:989-95.

10. Wiersinga WM, Prummel MF, Terwee CB. Effects of Graves' ophthalmopathy on quality of life. J Endocrinol Invest. 2004;27:259-64.

11. Bahn RS. Is orbital decompression a safe and effective treatment for Graves' orbitopathy? Nat Clin Pract Endocrinol Metab. 2007;3:796-7.

12. Bartalena L. Graves' orbitopathy: imperfect treatments for a rare disease. Eur Thyroid J. 2013;2:259-69.

13. Dharmasena A, Keenan TD, Goldacre MJ. Orbital decompression for thyroid-associated orbitopathy in England: trends over time and geographical variation. Orbit. 2014;33:109-14.

14. Eckstein A, Schittkowski M, Esser J. Surgical treatment of Graves' ophthalmopathy. Best Pract Res Clin Endocrinol Metab. 2012;26:339-58.

15. Goldberg RA. The evolving paradigm of orbital decompression surgery. Arch Ophthalmol. 1998;116:95-6.

16. Kim KW, Byun JS, Lee JK. Surgical effects of various orbital decompression methods in thyroid-associated orbitopathy: computed tomography-based comparative analysis. J Craniomaxillofac Surg. 2014;42:1286-91.

17. Marcocci C, Altea MA, Leo M. Treatment options for Graves' orbitopathy. Expert Opin Pharmacother. 2012;13:795-806.

18. Verity DH, Rose GE. Acute thyroid eye disease (TED): principles of medical and surgical management. Eye (Lond). 2013;27:308-19.

19. Baldeschi L, MacAndie K, Hintschich $\mathrm{C}$, et al. The removal of the deep lateral wall in orbital decompression: its contribution to exophthalmos reduction and influence on consecutive diplopia. Am J Ophthalmol. 2005;140:642-7.

20. Boboridis KG, Gogakos A, Krassas GE. Orbital fat decompression for Graves' orbitopathy: a literature review. Pediatr Endocrinol Rev. 2010;7(Suppl 2):222-6.

21. O'Malley MR, Meyer DR. Transconjunctival fat removal combined with conservative medial wall/ floor orbital decompression for Graves orbitopathy. Ophthal Plast Reconstr Surg. 2009;25:206-10.

22. Boboridis KG, Bunce C. Surgical orbital decompression for thyroid eye disease. Cochrane Database Syst Rev. 2011. doi:10.1002/14651858. CD007630.pub2:CD007630.
23. Fichter N, Guthoff RF, Schittkowski MP. Orbital decompression in thyroid eye disease. ISRN Ophthalmol. 2012;2012:739236.

24. Garrity JA. Orbital lipectomy (fat decompression) for thyroid eye disease: an operation for everyone? Am J Ophthalmol. 2011;151:399-400.

25. Mehta P, Durrani OM. Outcome of deep lateral wall rim-sparing orbital decompression in thyroid-associated orbitopathy: a new technique and results of a case series. Orbit. 2011;30:265-8.

26. Perumal B, Meyer DR. Treatment of severe thyroid eye disease: a survey of the American Society of Ophthalmic Plastic and Reconstructive Surgery (ASOPRS). Ophthal Plast Reconstr Surg. 2014;. doi:10.1097/IOP.0000000000000216.

27. Prat MC, Braunstein AL, Glass LR, et al. Orbital fat decompression for thyroid eye disease: retrospective case review and criteria for optimal case selection. Ophthal Plast Reconstr Surg. 2014. doi:10.1097/ IOP.0000000000000260.

28. European Group on Graves Orbitopathy, Mourits $\mathrm{MP}, \mathrm{Bijl} \mathrm{H}$, et al. Outcome of orbital decompression for disfiguring proptosis in patients with Graves' orbitopathy using various surgical procedures. Br J Ophthalmol. 2009;93:1518-23.

29. Hurwitz JJ, Birt D. An individualized approach to orbital decompression in Graves' orbitopathy. Arch Ophthalmol. 1985;103:660-5.

30. Moher D, Liberati A, Tetzlaff J, et al. Preferred reporting items for systematic reviews and meta-analyses: the PRISMA statement. 2009.

31. Marcocci C, Bartalena L, Tanda ML, et al. Comparison of the effectiveness and tolerability of intravenous or oral glucocorticoids associated with orbital radiotherapy in the management of severe Graves' ophthalmopathy: results of a prospective, single-blind, randomized study. J Clin Endocrinol Metab. 2001;86:3562-7.

32. Prummel MF, Terwee CB, Gerding MN, et al. A randomized controlled trial of orbital radiotherapy versus sham irradiation in patients with mild Graves' ophthalmopathy. J Clin Endocrinol Metab. 2004;89:15-20.

33. Rajendram R, Lee RW, Potts MJ, et al. Protocol for the combined immunosuppression and radiotherapy in thyroid eye disease (CIRTED) trial: a multi-centre, double-masked, factorial randomised controlled trial. Trials. 2008;9:6.

34. Werner SC. Modification of the classification of the eye changes of Graves' disease: recommendations of the ad hoc committee of the American Thyroid 
Association. J Clin Endocrinol Metab. 1977;44:203-4.

35. Prummel MF, Mourits MP, Berghout A, et al. Prednisone and cyclosporine in the treatment of severe Graves' ophthalmopathy. N Engl J Med. 1989;321:1353-9.

36. Mourits MP, Prummel MF, Wiersinga WM, et al. Clinical activity score as a guide in the management of patients with Graves' ophthalmopathy. Clin Endocrinol (Oxf). 1997;47:9-14.

37. Terwee CB, Gerding MN, Dekker FW, et al. Development of a disease specific quality of life questionnaire for patients with Graves' ophthalmopathy: the GO-QOL. Br J Ophthalmol. 1998;82:773-9.

38. Glanville JM, Lefebvre C, Miles JN, et al. How to identify randomized controlled trials in medline: ten years on. J Med Libr Assoc. 2006;94:130-6.

39. Higgins JP, Altman DG, Gotzsche PC, et al. The Cochrane Collaboration's tool for assessing risk of bias in randomised trials. BMJ. 2011;343:d5928.

40. Deeks JJ, Higgins JPT, Altman DG. Analysing data and undertaking meta-analyses. In: Higgins JP, Green S (eds). Cochrane handbook for systematic reviews of interventions Version 510. The Cochrane Collaboration; 2011. http://www.cochranehandbook.org. Accessed 24 Jan 2015

41. Pliego-Maldonado A, Miranda-Ruiz R, Vargas-Aguayo A, et al. Orbit decompression surgery in patients with exophthalmos caused by Graves-Basedow disease. Gac Med Mex. 2000;136:11-5.

42. Wakelkamp IM, Baldeschi L, Saeed P, et al. Surgical or medical decompression as a first-line treatment of optic neuropathy in Graves' ophthalmopathy? A randomized controlled trial. Clin Endocrinol (Oxf). 2005;63:323-8.

43. Barkhuysen R, Nielsen CC, Klevering BJ, et al. The transconjunctival approach with lateral canthal extension for three-wall orbital decompression in thyroid orbitopathy. J Craniomaxillofac Surg. 2009;37:127-31.

44. Cansiz H, Yilmaz S, Karaman E, et al. Three-wall orbital decompression superiority to 2-wall orbital decompression in thyroid-associated ophthalmopathy. J Oral Maxillofac Surg. 2006;64:763-9.

45. Chu EA, Miller NR, Grant MP, et al. Surgical treatment of dysthyroid orbitopathy. Otolaryngol Head Neck Surg. 2009;141:39-45.
46. Clauser L, Galie M, Sarti E, et al. Rationale of treatment in Graves ophthalmopathy. Plast Reconstr Surg. 2001;108:1880-94.

47. Russo V, Querques G, Primavera V, et al. Incidence and treatment of diplopia after three-wall orbital decompression in Graves' ophthalmopathy. J Pediatr Ophthalmol Strabismus. 2004;41:219-25.

48. Thaller SR, Kawamoto HK. Surgical correction of exophthalmos secondary to Graves' disease. Plast Reconstr Surg. 1990;86:411-8 (discussion 19-21).

49. Kingdom TT, Davies BW, Durairaj VD. Orbital decompression for the management of thyroid eye disease: an analysis of outcomes and complications. Laryngoscope. 2015. doi:10.1002/ lary.25320.

50. Gulati S, Ueland $\mathrm{HO}$, Haugen $\mathrm{OH}$, et al. Long-term follow-up of patients with thyroid eye disease treated with endoscopic orbital decompression. Acta Ophthalmol. 2015;93:178-83.

51. Roncevic R, Savkovic Z, Roncevic D. Results of diplopia and strabismus in patients with severe thyroid ophthalmopathy after orbital decompression. Indian J Ophthalmol. 2014;62:268-73.

52. Mainville NP, Jordan DR. Effect of orbital decompression on diplopia in thyroid-related orbitopathy. Ophthal Plast Reconstr Surg. 2014;30:137-40.

53. Fabian ID, Rosen N, Ben Simon GJ. Strabismus after inferior-medial wall orbital decompression in thyroid-related orbitopathy. Curr Eye Res. 2013;38:204-9.

54. Silbert DI, Matta NS, Singman EL. Diplopia secondary to orbital surgery. Am Orthopt J. 2012;62:22-8.

55. Maino AP, Dawson EL, Adams GG, et al. The management of patients with thyroid eye disease after bilateral orbital 3 wall decompression. Strabismus. 2011;19:35-7.

56. Lukas K, Hansrudi N, Alexander S, et al. A step towards individualized, anatomy-based surgical concepts for orbital decompression in Graves' orbitopathy. Orbit. 2009;28:237-40.

57. Liao SL, Shih MJ, Chang TC, et al. Transforniceal lateral deep bone decompression-a modified technique to prevent postoperative diplopia in patients with disfiguring exophthalmos due to dysthyroid orbitopathy. J Formos Med Assoc. 2006;105:611-6. 
58. Goldberg RA, Weinberg DA, Shorr N, et al. Maximal, three-wall, orbital decompression through a coronal approach. Ophthalmic Surg Lasers. 1997;28:832-43.

59. Kakizaki $\mathrm{H}$, Takahashi $\mathrm{Y}$, Ichinose $\mathrm{A}$, et al. The importance of rim removal in deep lateral orbital wall decompression. Clin Ophthalmol. 2011;5:865-9.

60. Ben Simon GJ, Syed HM, Lee S, et al. Strabismus after deep lateral wall orbital decompression in thyroid-related orbitopathy patients using automated hess screen. Ophthalmology. 2006;113:1050-5.

61. Ben Simon GJ, Wang L, McCann JD, et al. Primary-gaze diplopia in patients with thyroid-related orbitopathy undergoing deep lateral orbital decompression with intraconal fat debulking: a retrospective analysis of treatment outcome. Thyroid. 2004;14:379-83.

62. Baril C, Pouliot D, Molgat Y. Optic neuropathy in thyroid eye disease: results of the balanced decompression technique. Can J Ophthalmol. 2014;49:162-6.

63. Cascone P, Rinna C, Reale G, et al. Compression and stretching in Graves orbitopathy: emergency orbital decompression techniques. J Craniofac Surg. 2012;23:1430-3.

64. Choe CH, Cho RI, Elner VM. Comparison of lateral and medial orbital decompression for the treatment of compressive optic neuropathy in thyroid eye disease. Ophthal Plast Reconstr Surg. 2011;27:4-11.

65. Graham SM, Carter KD. Combined endoscopic and subciliary orbital decompression for thyroid-related compressive optic neuropathy. Rhinology. 1997;35:103-7.

66. Korkmaz S, Konuk O. Surgical treatment of dysthyroid optic neuropathy: long-term visual outcomes with comparison of 2-wall versus 3-wall orbital decompression. Curr Eye Res. 2015. doi:10. 3109/02713683.2015.1008641:1-6.

67. Perumal B, Meyer DR. Treatment of severe thyroid eye disease: a survey of the American Society of Ophthalmic Plastic and Reconstructive Surgery (ASOPRS). Ophthal Plast Reconstr Surg. 2015;31:127-31.

68. Chang EL, Bernardino CR, Rubin PA. Transcaruncular orbital decompression for management of compressive optic neuropathy in thyroid-related orbitopathy. Plast Reconstr Surg. 2003;112:739-47.

69. Eloy P, Trussart C, Jouzdani E, et al. Transnasal endoscopic orbital decompression and Graves' ophtalmopathy. Acta Otorhinolaryngol Belg. 2000;54:165-74.

70. Hurwitz JJ, Freeman JL, Eplett CJ, et al. Ethmoidectomy decompression for the treatment of Graves' optic neuropathy. Can J Ophthalmol. 1992;27:283-7.

71. Liao SL, Chang TC, Lin LL. Transcaruncular orbital decompression: an alternate procedure for Graves ophthalmopathy with compressive optic neuropathy. Am J Ophthalmol. 2006;141:810-8.

72. Lv Z, Selva D, Yan W, Daniel P, Tu Y, Wu W. Endoscopical orbital fat decompression with medial orbital wall decompression for dysthyroid optic neuropathy. Curr Eye Res. 2015;1-9. doi:10.3109/ 02713683.2015.1008640.

73. McCann JD, Goldberg RA, Anderson RL, et al. Medial wall decompression for optic neuropathy but lateral wall decompression with fat removal for non vision-threatening indications. Am J Ophthalmol. 2006;141:916-7.

74. Shorr N, Baylis HI, Goldberg RA, et al. Transcaruncular approach to the medial orbit and orbital apex. Ophthalmology. 2000;107:1459-63.

75. Olivari N. Transpalpebral decompression of endocrine ophthalmopathy (Graves' disease) by removal of intraorbital fat: experience with 147 operations over 5 years. Plast Reconstr Surg. 1991;87:627-41 (discussion 42-43).

76. Olivari N. Thyroid-associated orbitopathy: transpalpebral decompression by removal of intraorbital fat. Experience with 1362 orbits in 697 patients over 13 years. Exp Clin Endocrinol Diabetes. 1999;107(Suppl 5):S208-11.

77. Richter DF, Stoff A, Olivari N. Transpalpebral decompression of endocrine ophthalmopathy by intraorbital fat removal (Olivari technique): experience and progression after more than 3000 operations over 20 years. Plast Reconstr Surg. 2007;120:109-23.

78. Adenis JP, Robert PY, Lasudry JG, et al. Treatment of proptosis with fat removal orbital decompression in Graves' ophthalmopathy. Eur J Ophthalmol. 1998;8:246-52.

79. Ferreira MC, Tuma P Jr, Costa MP, et al. Surgical treatment of endocrine exophthalmos by removal of orbital fat: clinical experience. Rev Hosp Clin Fac Med Sao Paulo. 2002;57:217-22.

80. Trokel S, Kazim M, Moore S. Orbital fat removal. Decompression for Graves orbitopathy. Ophthalmology. 1993;100:674-82. 
81. Wu CH, Chang TC, Liao SL. Results and predictability of fat-removal orbital decompression for disfiguring Graves exophthalmos in an asian patient population. Am J Ophthalmol. 2008;145:755-9.

82. Kazim M, Trokel SL, Acaroglu G, et al. Reversal of dysthyroid optic neuropathy following orbital fat decompression. Br J Ophthalmol. 2000;84:600-5.

83. Dickersin K, Min YI, Meinert CL. Factors influencing publication of research results. Follow-up of applications submitted to two institutional review boards. JAMA. 1992;267:374-8.

84. Takahashi Y, Kakizaki H. Horizontal eye position in thyroid eye disease: a retrospective comparison with normal individuals and changes after orbital decompression surgery. PLoS One. 2014;9:e114220.

85. Hill RH, Czyz CN, Bersani TA. Transcaruncular medial wall orbital decompression: an effective approach for patients with unilateral Graves ophthalmopathy. Sci World J. 2012;2012:312361.

86. Unal M, Leri F, Konuk O, et al. Balanced orbital decompression combined with fat removal in Graves ophthalmopathy: do we really need to remove the third wall? Ophthal Plast Reconstr Surg. 2003;19:112-8.

87. Asaria RH, Koay B, Elston JS, et al. Endoscopic orbital decompression for thyroid eye disease. Eye (Lond). 1998;12(Pt 6):990-5.

88. Cruz AA, Leme VR. Orbital decompression: a comparison between trans-fornix/transcaruncular inferomedial and coronal inferomedial plus lateral approaches. Ophthal Plast Reconstr Surg. 2003;19:440-5 (discussion 45).

89. Lee KY, Ang BT, Ng I, et al. Stereotaxy for surgical navigation in orbital surgery. Ophthal Plast Reconstr Surg. 2009;25:300-2.

90. Millar MJ, Maloof AJ. The application of stereotactic navigation surgery to orbital decompression for thyroid-associated orbitopathy. Eye (Lond). 2009;23:1565-71.

91. Wu CY, Kahana A. Stereotactic navigation with a registration mask in orbital decompression surgery: preliminary results. Ophthal Plast Reconstr Surg. 2015; . doi:10.1097/IOP.0000000000000369.

92. Cho RI, Choe $\mathrm{CH}$, Elner VM. Ultrasonic bone removal versus high-speed burring for lateral orbital decompression: comparison of surgical outcomes for the treatment of thyroid eye disease. Ophthal Plast Reconstr Surg. 2010;26:83-7.

93. Nguyen J, Fay A, Yadav P, et al. Stereotactic microdebrider in deep lateral orbital decompression for patients with thyroid eye disease. Ophthal Plast Reconstr Surg. 2014;30:262-6.

94. Ponto KA, Zwiener I, Al-Nawas B, et al. Piezosurgery for orbital decompression surgery in thyroid associated orbitopathy. J Craniomaxillofac Surg. 2014;42:1813-20.

95. Rocchi R, Lenzi R, Marino M, et al. Rehabilitative orbital decompression for Graves' orbitopathy: risk factors influencing the new onset of diplopia in primary gaze, outcome and patients' satisfaction. A large retrospective study. Thyroid. 2012;. doi:10. 1089/thy.2012-0272.

96. Murchison AP, Schaberg M, Rosen MR, et al. Large meningoencephalocele after orbital decompression. Ophthal Plast Reconstr Surg. 2012;28:e64-5.

97. Baldeschi L. Small versus coronal incision orbital decompression in Graves' orbitopathy. Orbit. 2009;28:231-6.

98. Goldberg RA, Perry JD, Hortaleza V, et al. Strabismus after balanced medial plus lateral wall versus lateral wall only orbital decompression for dysthyroid orbitopathy. Ophthal Plast Reconstr Surg. 2000;16:271-7.

99. Stark B, Olivari N. Treatment of exophthalmos by orbital fat removal. Clin Plast Surg. 1993;20:285-9 (discussion 90).

100. Kazim M, Trokel SL, Acaroglu G, et al. Reversal of dysthyroid optic neuropathy following orbital fat decompression. Br J Ophthalmol. 2000;84:600-5. 